\title{
GOD'S NOT DEAD 1 - OPEN EDUCATION MODEL OF RELIGIOUS EDUCATION IN THE WORLD OF MIXED VALUES
}

\author{
IWONA ZAMKOWSKA \\ Faculty of Philology and Pedagogy, \\ Kazimierz Pulaski University of Technology and Humanities in Radom \\ ul. Chrobrego 31, 26-600 Radom, Poland \\ Email address: i.zamkowska@uthrad.pl \\ ORCID: https://orcid.org/0000-0002-2595-1035
}

\begin{abstract}
Aim. The aim of the research is to explore the functionality of the Open Education Model of religious education for the "form[ation of] an internal moral compass," as Steven Hitlin and Jane Allyn Piliavin (2004) describe the modern understanding of values. In other words, the author will attempt to explore first what the model has to offer in terms of equipping students with the necessary skills so that they will successfully navigate through the conflict of values, and second the potential application and limitations of the model.

Methods. The exploration is based on a 2014 production by Pure Flix Entertainment, the first movie in the God's not Dead series. The author will consider two educational cases presented in the movie using a close reading method.

Results. The study seems to prove that that the God's not Dead movie accurately portrays the conflict of values experienced by young adults in present-day America. It also appears to consistently promote the Open Education Model as a type of religious education that provides considerable assistance to the learners in retaining their beliefs in the world of mixed values, especially in the time of crisis. The model appears to lend sound conceptual framework missing in other models, but its full application is time and effort consuming and fails to provide more comprehensive approach to religious diversity.

Conclusion. The Open Education Method of religious instruction in the environment dominated by a multicultural approach, seems to offer valuable concepts that may facilitate educational process proposed by other models and thus deserves more thorough consideration in academic research.
\end{abstract}

Key words: Religious education, mixed values, absolutism, relativism, Open Education Model

\section{INTRODUCTION}

Talues, in sociological terminology, constitute a universal element of culture. As related to individuals, they are understood as social behaviour

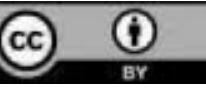


that is partly motivated by dominant values and ideologies (Leung \& Bond, 1989; Griffiths \& Keirns, 2015). In this sense values are defined as "desirable, transsituational goals, varying in importance, that serve as guiding principles in people's lives" (Schwartz \& Bardi, 2001, p. 269; Griffiths \& Keirns, 2015, p. 41). Values represented by individual citizens contribute to the system of values at a national level, and are defined as "shared, abstract ideas of what is good, right, and desirable in a society" (Knafo, Roccas, \& Sagiv, 2011, p. 179). Even though the term is originally ascribed to the discipline of sociology, the paper will examine the concept of values from cultural and educational perspective. The main object of analysis will be the first part of a 2014 PureFlix production God's not Dead. The analysis will be conducted using close reading method. Both individual and national dimension will be considered to explore to what extend individual values of protagonists are reflected in the national value system of the United States.

The initial section of the paper will focus on the analysis of the accuracy of the movie portrayal of American society as a nation of mixed values. First, the two dominant value systems will be presented, namely absolutism and relativism. Special attention will be given to the role that religion plays in the formation of these moral visions of United States citizens. In order to present the distribution of the followers of the two dominant options, the results of the World Value Survey related to the United States will be considered in the context of American society as a whole. Since the movie plot is set at a state college, and the main protagonists are connected to a Protestant faith tradition, the survey results for the adherents to Protestantism in general and Protestant youth in particular will be given special attention. The author will also attempt to analyze the validity of the movie portrayal of the clash of values against the backdrop of scholarly works.

The production seems to pursue the goal of heightening public awareness of the existence of mixed or even conflicting values in the public sphere - more specifically in the educational context - and the challenge it poses to the adherents to Christian values. Directed by Harold Cronk (2014) the movie is a drama that follows a story of a young Christian by the name of Josh Wheaton who is a college freshman at a state university. In the first lecture in the philosophy course the class is publicly confronted in the area of the origins and development of life by their instructor, Professor Radisson, a declared atheist. Josh is the only student that decides to take the challenge, despite the fact that it carries a risk of his failing the course and thus ruining his career plans. In his inner struggle, the student is assisted by an evangelical pastor, by the name of Dave, who helps him understand the significance of his experience and engage in the self-discovery of the solution. The first question the author of the paper will thus attempt to answer will be whether the value-related confrontations presented in the movie accurately reflect the divide and conflict of values in present-day American society both in the general as well as educational contexts.

Since the topic of the mixed values is debated within the context of religious education, the next section will be devoted to the analysis of the form 
of religious instruction adopted in the movie and how it relates to the forms discussed in the literature and ones adopted by the US state school system and religious communities. The next area under consideration will thus involve religious education systems and what they have to offer in terms of instructing students on how to successfully address value conflicts both in their private and study life. The main objective here will be first to determine whether an experience-based type of religious instruction presented in the movie has been recognized in American religious education theory, and second, to explore its possible applications and limitations for the educational process.

In sum, the author of the paper will attempt to answer the following main questions:

- Does the movie portrayal of the confrontations between the two worldviews, absolutism and relativism accurately reflect the dynamics of American society in this respect?

- Has the Open Education Model been successfully modelled by in the movie?

- What are the possible applications and limitations of the model in comparison with other models of religious education functioning in the United States?

\section{PORTRAYAL OF THE AMERICAN SOCIETY AS A NATION OF MIXED VALUES}

The context of mixed values is introduced in the movie from the very first scene. Josh, whose Christian views are made evident to a fellow student in the registration team as he notices a cross on the freshman's neck, is warned of the atheistic views of his instructor in the philosophy course and advised to elect a different lecturer. As the story unfolds, the viewers are introduced to more side stories also heavily charged by value conflict. One of them involves Mina, Professor Radisson's romantic partner. A Christian herself, she is torn between her beliefs and her partner's atheistic views. The same dynamic can be observed between Mina's mother, a strong believer in God, and Mina's brother, a self-reliant businessman.

The movie depiction of two contrasting systems of values seems to correspond with the discussion of the duality of values in American society in scholarly literature. For instance, Wayne E. Baker (2008), an American author and sociologist, distinguishes two types of worldviews, or moral visions, that form the basis for moral values and moral judgement of US citizens. Both visions incorporate a belief that there exists moral authority located in an identifiable object. One of the visions, colloquially referred to as absolutism, locates the source of moral values in entities external to an individual, in the metaphysical realm, most commonly in God, society or abstract ideas. Like Josh and Mina, the proponents of this vision share a belief in the existence of a moral code that is universal and independent from individuals subjected to its requirements. 
Contrasted with this stand is the worldview of relativism, its counterpart in the same conceptual system. Unlike absolutists, relativists identify "mundane sphere" (Baker, 2008, p.11) as the source of moral authority. In other words, they claim that moral authority rests within individuals and situations they find themselves in locally. Resultantly, there does not exist one moral code, rather multiple codes that depend on the individual, the times they live in and the situations they find themselves in as they face the challenges and struggles of life. This kind of value system is consistently portrayed in the movie on the example of Professor Radisson and Mina's brother, particularly in the area of relations where their loyalty is subjected to change depending on the circumstances.

A similar value dichotomy is adopted by authors of the World Value Survey. In so much as for Baker absolutism and relativism constitute elements of the same system, in the survey, traditionalism is coupled with a secular-rational dimension. Societies that cherish "traditional values" are defined by the Survey authors as stressing the significance of religion, parent-child relations, acquiescence to authority as well as traditional family value. Ones that embrace "secular-rational values", in turn, are synonymous with attaching less importance to religion, traditional family values and authority (The World Values Survey Association, n.d.).

As evident in the above definitions, religion constitutes a distinctive component of the traditional versus secular-rationalist value dichotomy. Those who hold traditional values typically express the preeminence of religion and God in the life of an individual. They will identify themselves as religious people and specify religion as their source of trust and strength. Josh, pastor Dave, Mina and her mother appear to model this type of attitude as they rely on the Supreme Being for direction, courage and support, particularly in the time of distress. Traditionalists will also place great trust in the country's churches and be regular churchgoers. This particular feature is not emphasized in the movie as apart from one scene there is no evidence that the protagonists representing traditional value system are regular church attendees.

Since in the traditional system of values the belief in God is strongly corelated with country and family, its adherents will also attach a great deal of importance to patriotism and family values. The latter would include the pro-life and anti-abortion position, as well as the belief that children are supposed to be instructed on how to show obedience and respect, and are expected to determine that making their parents proud will be the main purpose of their life (Baker, 2008). Apparently more often than not will moral absolutists be identified as traditional values holders, while the proponents of secular-rational values will embrace the rationalist position and will consequently stress the opposite views on all of the above-mentioned topics. Having established that the dual system of values portrayed in the movie is the accurate reflection of the dichotomy present in American society, it seems well-grounded to ask more detailed questions about the proportions of the followers of these value systems and the current trends in this area. 


\section{THE DISTRIBUTION OF ADHERENTS TO BOTH VALUE SYSTEMS}

Analyzing the representation of the proponents of the traditional position in the movie, one may easily conclude that - at least in the public square - absolutists constitute a fraction of otherwise secularized society. Initially, Josh is the only student who is determined to stay faithful to his Christian beliefs, and so does Mina. However, the body of research appears to provide only partial evidence of that. On the one hand, America - Baker (2008) believes - has no equal when it comes to its perception of moral authority and, as such, is recognized as one of the nations with the strongest absolutist position. Since absolutism is associated with traditionalism, it also places American society among the most traditional ones. The author identifies the preeminence of early settlers' system of values over American culture and institutions as the root of these beliefs (Baker, 2008). The foundational character of the traditional set of ideas and values makes its sustainment essential to the preservation of the nation's "ideological core," (Baker, 2008, p. 28) he concludes.

The statement on the prevalence of religious values in American society seems to be confirmed by the results of the value survey. The data shows that a significant representation of Americans, i.e. $76 \%$, claim that they believe in God (Haerpfer et al., 2020). For a quarter of the population God constitutes a very important part of their life, and $36 \%$ percent make the same declaration about religion. As many as $58 \%$ perceive themselves as religious. When it comes to religious practices, approximately one third of respondents claim that they are active members of church or a religious organization and roughly the same number of respondents declare participation in religious services at least once a week, while a little over $60 \%$ claim they pray more than several times each week.

In relation to Protestants, whose faith is featured in the God's not Dead production, they seem to be more religious than the society in general as they score higher in almost all categories, apart from identifying religion as a very important aspect of their lives and attending religious services at least once a week. Young Protestants, whose religious education is the main focus of this paper, also score higher than the general population and slightly lower than Protestants in general, apart from the significance of religion and religious service attendance (Haerpfer et al., 2020).

However, as Baker (2008) contends, the majority of Americans are of the opinion that traditional values experience a decline in the US society which have been or are being lost to the more relativist position. The thesis seems to correspond with the results of Wave 7 of the value survey conducted between 2017-2020 (Haerpfer et al., 2020) as compared to Wave 6 carried out between 2010-2014 (Inglehart et al., 2014). The results evidence the downhill trend in religious values, particularly as the focus narrows down to the younger generation. Young people appear to show a contrasting tendency to Protestants en masse, scoring lower than the general population in all categories save for religious service attendance. 
Thus, on the one hand, religion as a traditional value continues to hold a high position in the system of values in American society, but on the other, these values are less evident in the younger generation, thus creating a generational gap. The World Values Survey findings seem to correspond with the latest Pew Forum research, which evidences a growing gap between generations as far as religious involvement is concerned. The process of graying of congregations in the United States has been ongoing for decades, as the authors of the report state (Pew Research Center, 2018). Young adults have been found to show much less attachment to religion than the previous generation. Their identification with religion, belief in God and engagement in religious practices tend to be less. For instance, the findings have evidenced that $44 \%$ of young adults engage in daily prayer, compared with $62 \%$ of those ages 40 and older. The substantial gap is identified in lower religious services attendance as well as daily prayer practice, with a $20 \%$ difference between the generations.

As evident from the analysis so far, the movie appears to misrepresent the proportion of absolutist in American society as the statistical data testifies to the fact that Americans continue to hold traditional values, with religion as its integral part, in high esteem. However, it seems to accurately portray the downward trend, visible particularly in the generation of young people who tend to be less religious than their parents and grandparents.

\section{THE CLASH OF VALUE SYSTEMS}

The dual system of values is represented in the movie as the area of conflict. Not only is the Christian minority underrepresented; it is heavily oppressed. As early as in the enrollment scene, the prospects of Josh's participation in Professor Radisson's lectures are likened to the experience of persecution of early Christians: "Think Roman Colosseum, lions, people cheering for your death," (Cronk, 2014, "Course Enrollment Scene") hears Josh. The remaining part of the movie abounds in clashes between the proponents of the two options.

The main confrontation starts during Professor Radisson's first lecture (Cronk, 2014, "First Lecture Scene"), when the academic presents his case for secular-rational values. To start with, he enumerates a number of scholars, each of them officially rendered atheists or agnostics. He further pursues his argumentation making his own stand on the non-existence of God, calling him "the big man in the sky, the myth of a benevolent, all-powerful, supernatural being," (Cronk, 2014, "First Lecture Scene") someone who "never existed in the first place" (Cronk, 2014, "First Lecture Scene"). God's existence is rendered as a product of "the depths of our forebears' imaginations," (Cronk, 2014, "First Lecture Scene") something that belongs to the past when people resorted to it in order to explain the calamities that struck the earth. As such, faith in God has to be perceived as nothing more than "primitive superstition" (Cronk, 2014, "First Lecture Scene") that has now been "supplanted by science and reason," (Cronk, 2014, "First Lecture Scene") the supplanting that benefits us all, argues the lecturer. 
The concept of the conflict between the moral codes is highly contested in scholarly literature. On one side of the spectrum there are those who support the existence of the collision over values in the public square. Baker (2008), for instance, points out that in the present-day American society the existence of this dual system is evidenced in the "culture war." Karen Sullenger et al. (2000) define it as a way of describing conflicting perspectives that have their source in differences related to the perception of values, that is in defining right and wrong, good and evil. Some authors, Baker (2008) claims, identify the source of the conflict as the clash between absolutism and relativism. James Davison Hunter, Alan Wolfe, Michael Cromartie and E. J. Dionne Jr. (2006, p. 251), for instance, describe it as "competing understandings of the good and how the good is grounded and legitimated."

Os Guinness (2013) supports the idea that the conflict is religious in nature and involves two opposing visions of the relation between religion and public life. On one side of the conflict, there are those who opt for the elimination of religion and religious expression from the public sphere and on the other, those who would grant selected religion and ideology a privileged and dominant position. Richard John Neuhaus, the author states, would refer to the former as the proponents of the naked public square, and the latter the advocates of the sacred public square.

Steven D. Smith (2014), in turn, defines the conflict in terms of the polarisation of citizens into providentialist and secularist positions. As Hunter suggests, what is central to this new axis of tension is no longer divisions across denominational lines, into Protestants, Catholics and Jews, but rather cultural concerns. Resultantly, he explains, "The orthodox traditions in these faiths now have much more in common with each other than they do with progressives in their own faith traditions, and vice versa" (Hunter, Wolfe, Cromartie, \& Dionne, 2006, p. 254).

Not all authors will agree with the statement that the phenomenon of culture wars does actually exist in the American public square. Morris P. Fiorina, Samuel J. Abrams and Jeremy C. Pope (2011), for instance, question the idea, claiming that there is no war waged for the soul of American people that the citizens are conscious of. In the same vein, the author argues that the polarisation is limited to top party administration and is barely reflected in American society.

Similarly, Alan Wolfe contends that the majority of American citizens are neither aware of nor express any real interest in a partisan culture war, nor do they sympathise with any particular side. The important cultural conflicts, the author suggests, are not relational in nature but take a form of inner strive for living purposeful life and making personal choices regarding crucial issues such as life, death, relationships and family. The author refutes the idea that the differences are religious in nature, and should be dealt with by resorting to the cherished common values of tolerance, pluralism, and commitment to individualism, and coming to an agreement by regular members of the society (The Pew Forum on Religion and Public Life, 2007). 
In the movie, the sector of the public square mostly affected by value conflict is public education. The body of research seems to be in agreement with this portrayal as many authors identify public education as the domain of public life that has been most central to this conflict over values. Jonathan Zimmerman (2005, p. 2267), for instance, claims that since the school is "America's chief public institution for distilling and delivering moral values to its young" it is natural that it was materially affected by the conflict. Even though there is no agreement on what issue actually initiated the conflict, some authors, like Smith (2014), point to the Supreme Court's decisions in striking down state-sponsored prayer, and the providentialists' angry response it evoked.

Even though apparently triggered by the conflict over school prayer, the spectrum of divisive issues within the culture war conflict is not limited to the legality of this religious practice on school premises. Over the years, it has included, among other things, the moral content of textbooks, including sex education, equal access for Bible-reading and school clubs, public funding for religious education, to name a few. Most recently, the focus of the value conflict, Hunter (1992) argues, has been multiculturalism in the curriculum.

There are also scholars, who, like Hunter (1992), identify the infamous Scopes trial of 1926 over the teaching of evolution with the teaching of creationism as the very factor that triggered the modern value conflict in the area of education. The movie portrayal of the conflict suggests that this controversial issue continues to be highly contested in educational context. First Amendment scholars, like David L. Hudson Jr. (2006) would provide some support to this statement. Even though since the 1926 trial the controversy over origins of life has undergone significant transformation and taken many forms, states the author, the strength of its divisiveness remains the same.

Discussing the clash of ideas in the educational setting one cannot overlook the psychological aspect of the issue. In the movie, apart from purely ideological dimension, the tensions resulting from the collision of values add to the inner struggle of those involved and necessitate the search for assistance. As for Josh, the pressure begins to mount as Professor Radisson, to win the consensus of his students, requires all of them to submit a signed statement reading that "God is dead" (Cronk, 2014, "First Lecture Scene") and never existed. The request comes with the intimidating remark that the agreement of all students is expected and the sooner it is reached the better as it will allow the students to circumvent the part of the course that is known for the poorest performance.

Josh is the only student that takes a stand against Professor's views, claiming his being a Christian as the reason (Cronk, 2014, "First Lecture Scene"). As a result of his refusal to comply with the teacher's offer, he must face serious consequences. First, he will have to defend his traditional beliefs, namely "the antithesis that God is not dead," (Cronk, 2014, "First Lecture Scene") and second, to do it publicly. Failing to defend the antithesis will result in failing this class, and consequently, put his future study plans in jeopardy. To make the situation even more testing for the defying student, the lecturer attempts to evoke unfavorable feelings against him in the remaining course participants 
by assigning secularist literature to be read for the next class by means of the preparation for Josh's speech. Added to that is Josh's stormy relation with his girlfriend who threatens to leave him if he does not comply to professor's offer. Under tremendous pressure from all sides, Josh is troubled by conflicting emotions.

\section{RELIGIOUS EDUCATION MODEL IN GOD'S NOT DEAD}

The moral dilemma Josh faces creates a natural setting for religious instruction. Perplexed and fearful, he finds emotional refuge in the chapel of evangelical church. That is where he meets Pastor Dave, who offers assistance. Hearing Josh's evasive reply that he is waiting for someone supposedly missing, he immediately diagnoses a confused soul in search of the Supreme Being. As soon as he realizes that the young man feels that in actual fact it is God who is missing from his experience, the reverend makes himself available: "Well, maybe that's why he sent me" (Cronk, 2014, "Church Scene").

Josh shares his dilemma related to the challenge he faces in professor Radisson's class and with his girlfriend: "I could drop the class, run away, pretend like it never happened, which is what my girlfriend wants. I could sign the paper saying something I don't believe. Or I commit academic suicide in front of a live audience by trying to prove that God exists" (Cronk, 2014, "Church Scene"). Instead of offering a ready-made solution, Pastor Dave tries to facilitate Josh's interpretation of experience and provide the sources. To start with, he enquires about the number of students in professor Radisson's class to encourage a transition in Josh's perceptive on the situation from seeing it as a devastating experience into noticing it as an opportunity of "the only meaningful exposure to God and Jesus [his classmates] will ever have" (Cronk, 2014, "Church Scene"). The tone of the reverend's encouraging remarks are devoid of pressure, allowing Josh to make the final decision: "[I]f you decide to accept [this challenge] it may..." (Cronk, 2014, "Church Scene").

Finally, Pastor Dave provides the sources that would facilitate the self-discovery process. He requests Josh check two biblical references, the first from the Gospel of Matthew 10:32-33, and if "[he's] still undecided after that one," (Cronk, 2014, "Church Scene") the second from Luke 12:48. Since Josh is astonished by the simplicity of the Pastor's answer, and somewhat doubtful, the minister points him to the religious guidance he already has within his being, the voice of God that calls him to a relationship with the Supreme Being and prompts him to comprehend the religious significance of his religious experience: "You're here because that still small voice inside you isn't happy with the choices everyone else wants you to make" (Cronk, 2014, "Church Scene"). To clarify it further, the reverend adds: "Personally, I think it's the Holy Spirit talking to you. That's how he interacts with us if we allow him to" (Cronk, 2014, "Church Scene"). Here, the minister shares his own experience of recognition of the voice of God; however, he does not force Josh to follow the guid- 
ance of the Holy Spirit. Again, the point is made clear that the final decision belongs to the student: "All you have to do is decide whether or not you're willing to listen. It's not easy, but it's simple" (Cronk, 2014, "Church Scene").

Josh decides to follow Pastor Dave's instructions and continues the selfdiscovery process until he gets personally convinced by the Scripture to face the challenge. He texts the following message to Pastor Dave: "I'm going to give this a shot. What now?" (Cronk, 2014, scene 1). "Don't try to be clever. Be content to tell the truth," (Cronk, 2014, scene 1) the pastor instructs his student. Josh follows the instructions closely and does a thorough research into the subject spending many hours studying sources in the university library. As the story unfolds, he stands many tests: apparent failure to respond to $\mathrm{Mr}$ Radisson's question at the end of Josh's first presentation in front of the group, several instances of being harassed by his professor followed by a painful confrontation with his girlfriend who decides to break up their seven-year relationship (Cronk, 2014, scene 2). His forbearance pays off as he eventually wins the consent of his class to revoke their initial statement. One after another, they stand up to publicly declare that "God is not dead" (Cronk, 2014, "Final Debate Scene").

Another thread that involves religious education is Mina's conflict over religious values with her partner, Professor Radisson. The first confrontation comes her way as she decides to break the silence and touch on the taboo issue of value conflict in one-to-one conversation with her partner. The hidden emotions unearth again later on at a party in their apartment, in response to Radisson's mockery of a Christian student who publicly challenged the professor's views. Humiliated by her partner's cutting remarks on her faith, confused and brokenhearted, Mina decides to consult Pastor Dave. Through a series of probing questions he helps her to discover the source of her problem: "looking for [her partner's] approval to give [her] a sense of self-worth instead of generating it internally" (Cronk, 2014, scene 5). The reverend sees it as "an unstable foundation," (Cronk, 2014, scene 5) and suggests searching for self-worth in the right place. First, to consider God's unfailing love showed in the crucifixion of Jesus. And, second, determine which is the right person to seek affirmation from. "To the wrong person, you'll never have any worth. But to the right person, you'll mean everything," (Cronk, 2014, scene 5) clarifies the Pastor.

The first problem that needs to be considered here is whether Pastor Dave's instruction qualifies as religious education and whether it has its equivalent in educational theory. In relation to the first question, the scholarly literature seems to suggest that religious education may be interpreted as a very broad term that would include not only formal teaching in a school context but also both formal and informal religious nurturing within the confines of a family and/or religious community. Sylvie Langlaude (2007), for instance, discussing Robert Alexy's model of the rights of a child in the context of religious freedom in international law, identifies two modes of the religious nurturing process: formal and informal. As the author explains, informal nurturing occurs via religious observance in the home environment, while formal transmission of faith, 
via participation in the activities offered by religious communities (Langlaude, 2007). Thus, Pastor Dave's religious instruction can be broadly interpreted as informal education offered by the representative of a religious community.

As far as the reflection of the model in religious education theory, the classification of religious instruction devised by Robert R. Newton (1981) seems to offer valuable insight. The author points to the existence of four models of religious education that represent a usually implicit educational theory adopted by teachers built on their own religious education and their experience in teaching religion. This theory is closely related to values as it "forms the value structure which gives coherence and direction to the person's educational activities" (Newton, 1981, p. 1). Hence, all the models are value-oriented. The Open Education Model, however, seems to best correspond with the context presented in the source material as it puts emphasis on the development of students' capability to make their own religious and moral decisions. First, the model stresses the importance of students' own experience as the starting point of educational process. Just as it was the case with Josh and Mina, the initiative for growth comes from the learner. The environment, the message and the community rather than a predetermined curricular sequence are seen as stimulators of religious growth.

Second, it promotes the independent self-discovery approach to learning. The student is seen as "a discoverer and maker of his or her own religious meaning rather than a passive receptacle for the conclusions and insights of others" (Newton, 1981, p. 2). Deep within, an individual can hear the voice of God that calls them "into a relationship with the divine, prompting the individual to understand the religious significance of personal experience" (Newton, 1981, p. 2). This approach is evidenced both in the case of Josh and Mina. The life circumstances, and conflict of values in particular, encourage reflection on the value system they represent, prompt reassessment of the system and the need for prioritizing values in their life. Their reflection is recognized as the voice of God calling them to give him priority in their lives.

Another important element of the Open Education Model is that as the process of learning continues, life is seen as "a constant exploration, a striving to listen sensitively to a unique inner voice which prompts the individual to become all that he or she might be" (Newton, 1981, p. 2). Due to this religious self-discovery, students develop the ability of continuous reflection on experience, which leads to the creation of religious perspective that enables the students to "discern the religious and moral dimensions of that experience" (Newton, 1981, p. 3). For both Josh and Mina, the initial experience encourages the exploration of the guidance provided by the inner voice and facilitates their understanding of the moral and religious choices they are faced with.

As founded on the needs, questions, interests and experiences of students, the curriculum in the discussed model is more flexible and adaptable rather than pre-determined. Therefore, educators in this model need to qualify as deeply religious persons themselves, who having experienced God in their own life are able to provide assistance to students in their personal search for 
God by providing sources and answering questions in order to help students in their interpretation of experience. Their attitude is marked with reaffirmation and acceptance. As portrayed in the movie, both in the case of Josh and Mina, Pastor Dave, as a religious educator, provides assistance in their personal search for God, or for that matter, their search for a godly solution to a life problem. The assistance takes on the form of the provision of sources. For Josh, it involves referring him to some Scriptural references, while for Mina, offering a psychological explanation of her state of mind and religious explanation of the self-worth dilemma. The reverend, as an educator, provides answers to the students' questions that visibly facilitate their interpretation of experience as well as ensure much needed reaffirmation and acceptance. No directions as to the steps to take have been offered and the students are left to make decisions for themselves. However, both Josh and Mina, reassured by the instructions, decide to stand up for their beliefs.

\section{APPLICATION AND LIMITATIONS OF THE OPEN EDUCATIONAL MODEL}

The Open Education Model appears to offer some unique features but at the same time evidences some limitations. The first element of the model that is worth noticing is its practical approach to learning. Since the learning process is triggered by student's own experience, it takes advantage of real life challenges and uses them to create a natural learning environment. The student is thus highly motivated to seek and acquire relevant knowledge. In this sense, learning is naturally inspired by the necessity to solve a moral dilemma. Once the knowledge is acquired, it is almost instantly translated into action. If positive results are achieved, the student's motivation and openness to further exploration is increased.

The practicality of knowledge and experience-based approach make the model unique as they seem to be mostly missing in all other models discussed in literature, both ones specific for state schools and religious communities. The learning about religion model (Grimmitt, 2000), which is the only officially instituted type of religious education in American public schools (Hull, 2012), does not involve personal experience as religion is taught from the position of an outsider. Thus the experienced-based approach promoted by Open Education Model may be only applicable in out-of-school religious instruction where both curriculum and teaching methods are controlled by specific religious groups.

However, even in religious-community-run models discussed by Newton (1981) this practical and experience-based approach has limited application. In the Academic Model the focus is on the acquirement of knowledge about students' own religion, which does not leave space for experience. In the two remaining models, it is mainly a practical outcome, or targeted behaviour, that seems to be encouraged: in the Educational Technology Model, it is expected 
to take the form of the production of students' religious behaviour, and in the Social Justice Model, the form of the students' engagement in the solution of fundamental human problems.

Another characteristic feature of the Open Education model is student autonomy. First, the curriculum is adopted to the student's experience. Second, it encourages self-discovery and self-determination of the outcome. This feature is virtually non-present in other models presented in the literature, where both the curriculum and targeted outcome are pre-determined by educational authorities. The only trace of it can be found in Gabriel Moran's (2010) discussion of two distinct avenues of religious education, one of which involves the instruction in the practice of a specific religion and allows a personal decision to refrain from such practice.

The third core element of the Open Education Model is its strong emphasis on critical thinking and reflective approach to learning. Again, this element is virtually overlooked in knowledge- or behaviour-oriented religious-community-run models. As far as school-run models are concerned, learning about religion approach, John M. Hull (2012) argues, facilitates the development of students' critical thinking to be used for the interpretation of religious phenomena. By so doing, it helps to eliminate the beliefs adopted a priori, without previous examination, and to reconsider students' stereotypical thinking about other religions. As such, it has a significant role to play in the prevention of religious intolerance, the author concludes.

Finally, and possibly most importantly, the Open Education Model appears to attach critical importance to the notion of truth. Philip L. Barnes (2010) claims that serious approach to religious diversity has to involve a serious approach to religious truth in religious education. Rather than limiting education to the introduction to a wide spectrum of religious ideas and practices, this demand necessitates the development of skills and abilities of evaluating religious phenomena. What is missing in education, the author claims, is the development of a critical approach that enables students to recognize the arguments behind ideas and beliefs they are confronted with, to make thorough assessment and informed and wise choices. Considering the perspective presented in the movie, this argument seems to be critical when it comes to arriving at the right solution when one is faced with dilemmas, where there is virtually no possibility of reaching consensus, and decisions are seminal for the student's life.

As far as the limitations of the Open Education Model are concerned, it seems not to pay adequate attention to the provision of comprehensive education both in students' own faith tradition and the faith traditions of others. In this sense it does not properly prepare for living in the world marked with religious diversity. However, when complimented by more comprehensive religious education, it can facilitate religious learning in other settings by enhancing the use of critical thinking skills in the truth seeking process and reflective approach to life experiences. From the practical point of view, the model in its entirety seems to have limited application as it is time and effort consuming on the part of an educator. 
In school reality, the Open Education Model may not directly refer to college education level since formal religious education is not offered beyond high school. As the movie suggests, however, the need of addressing moral conflicts continues at college stage: university students still operate in the world of mixed values and face life challenges that directly refer to their value system based on religious beliefs. Therefore, there is a need of serious consideration of this problem in college environment. Informal education modelled in the movie may seem to be a valuable option to fill this gap. Appropriate provisions in the form of consultancy service should be made to adequately support students as they face moral dilemmas. This system should be based on respect and understanding of students' experience and ensure freedom of choice in making the final decision.

\section{CONCLUSION}

In sum, it seems justified to state that the God's not Dead movie accurately portrays the conflict of values experienced by young adults in present-day America. First, it corresponds with the literature on the subject of values in American society which points to the existence of the system of two competing moral visions that form the basis for moral values of the US citizens: absolutism and relativism, or using the terminology of the World Value Survey, the traditional values and secular-rational ones. Pastor Dave, Josh, and Mina are portrayed as individuals who look for moral authority in the transcendental sphere, while Professor Radisson is clearly the representative of a secular-rational option locating his moral authority in the self and local situation.

The movie provides an example of a culture-war between these two visions, most visible in the main conflict over the beginnings of life between Josh and Professor Radisson, but also in the tension over their stand on the Christian faith between the partners in two relationships: Josh and his girlfriend as well as the professor and his romantic partner, Mina. Due to the collision with values that are contrary to their own, the protagonists experience moral conflicts and dilemmas. Thus, an opportune setting for religious education that follows an Open Education model is created. The needs, questions and experiences of students determine the curriculum that is tailored to each individual situation, but in each case the reassurance that they can each hear the inner voice of God as well as acceptance are provided by the educator. Pastor Dave assists his students, mainly quoting Biblical verses, in understanding the religious significance of their personal experience, which the voice prompts them to do. This assisted self-discovery enables students to make their own choices and develop religious lenses that enable them to discern the religious and moral dimensions of that experience.

In the sector of religious education, now dominated by the multicultural approach, the Open Education Model illustrated in the movie seems to be a valuable alternative. In the case of American society, in the tumultuous Sixties 
it was the very ability to adhere to high moral standards, maintain a clear distinction between good and evil and a strong belief in Biblical truths that prepared evangelical youth to stand the test of mixed moral values. As Robert D. Putnam and David E. Campbell (2010, p. 113) explain: "The single most crucial element in the success of the evangelical movement after the long Sixties, we believe, was captured in St. Paul's exhortation to the Corinthians to stand firmly for their faith, 'for if the trumpet give an uncertain sound, who shall prepare himself to the battle?".

\section{REFERENCES}

[1] Baker, W. E. (2008). America the Traditional. In: T. Pettersson, \& Y. Esmer (Eds.), Changing values, persisting cultures: Case studies in value change (pp. 7-43). Leiden, Boston, Mass: Brill.

[2] Barnes, L. P. (2010). Enlightenment's Wake: Religion and Education at the Close of the Modern Age. In: W. K. Engebretson, M. de Souza, G. Durka, \& L. Gearon (Eds.), International Handbook of Inter-religious Education (pp. 25-40). Dordrecht: Springer.

[3] Cronk, H. (2014). God's not dead 1 [Drama]. Scottsdale: Pure Flix Entertainment.

[4] Fiorina, M. P., Abrams, S. J., \& Pope, J. C. (2011). Culture war? The myth of a polarized America. Boston, MA: Pearson Longman.

[5] Griffiths, H., \& Keirns, N. (2015). Introduction to Sociology 2e. Houston, Texas: OpenStax.

[6] Grimmitt, M. (2000). Contemporary Pedagogies of Religious Education: What are They?. In: M. Grimmitt (Ed.), Pedagogies of Religious Education (pp. 24-52). Great Wakering, England: McCrimmons Publishing.

[7] Guinness, O. (2013). The global public square: Religious freedom and the making of a world safe for diversity. Downers Grove, IL: InterVarsity Press.

[8] Haerpfer, C., Inglehart, R., Moreno, A., Welzel, C., Kizilova, K., Diez-Medrano J., Lagos, M., Norris, P., Ponarin, E., \& Puranen, B. et al. (Eds.). (2020). World Values Survey: Round Seven - Country-Pooled Datafile. Madrid, Spain \& Vienna, Austria: JD Systems Institute \& WVSA Secretariat.

[9] Hitlin, S., \& Piliavin, J. A. (2004). Values: Reviving a dormant concept. Annual Review of Sociology, 30(1), 359-393.

[10] Hudson Jr., D. L. (2006). Evolution and Creation. Retrieved July 27, 2020, from https:// www.freedomforuminstitute.org/first-amendment-center/topics/freedom-of-religion/ religious-liberty-in-public-schools/evolution-creation/

[11] Hull, J. M. (2012). The Contribution of Religious Education to Religious Freedom: A Global Perspective. Retrieved May 29, 2020, from https:/ /www.iarf.net/REBooklet/Hull.htm

[12] Hunter, J. D. (1992). Culture Wars the Struggle to Control the Family, Art, Education, Law, and Politics in America. New York: Basic Books.

[13] Hunter, J. D., Wolfe, A., Dionne Jr., E. J., \& Cromartie, M. (2006). Is there a culture war? A dialogue on values and American public life. Washington, D.C.: Brookings Institution Press.

[14] Inglehart, R., Haerpfer, C., Moreno, A., Welzel, C., Kizilova, K., Diez-Medrano, J., Lagos, M., Norris, P., Ponarin E., \& Puranen, B. (2014). World Values Survey: Round Six - Country-Pooled Datafile Version. Madrid: JD Systems Institute. Retrieved April 10, 2020 from https://www. worldvaluessurvey.org/WVSDocumentationWV6.jsp.

[15] Knafo, A., Roccas, S., \& Sagiv, L. (2011). The value of values in cross-cultural research: A special issue in honor of Shalom Schwartz. Journal of Cross-Cultural Psychology, 42 (2), 178-185.

[16] Langlaude, S. (2007). The Right of the Child to Religious Freedom in International law. Leiden, Boston: Martinus Nijhoff Publishers.

[17] Leung, K., \& Bond, M. H. (1989) On the empirical verification of dimensions for cross-cultural comparison. Journal of Cross-Cultural Psychology, 20(2), 133-151.

[18] Moran, G. (2010). Religious Education in United States' state schools. In: W. K. Engebretson, 
Journal of Education Culture and Society No. 2_2020

M. de Souza, G. Durka, \& L. Gearon (Eds.), International Handbook of Inter-religious Education [eBook edition] (pp. 141-153). Dordrecht: Springer.

[19] Newton, R. R. (1981). Four models of teaching religion. PACE, 11. Retrieved May 29, 2020, from http://hdl.handle.net/2345/2429.

[20] Pew Research Center. (2018). The age gap in religion around the world. Religion $\mathcal{E}$ Public Life. Retrieved May 29, 2020, from https://www.pewforum.org/2018/06/13/ young-adults-around-the-world-are-less-religious-by-several-measures/

[21] Putnam, R. D., \& Campbell, D. E. (2010). American grace: How religion divides and unites us. New York: Simon \& Schuster.

[22] Schwartz, S. H., \& Bardi, A. (2001). Value hierarchies across cultures: Taking a similarities perspective. Journal of cross cultural psychology, 32, 268-290.

[23] Smith, S. D. (2014). The rise and decline of American religious freedom. Cambridge, Mass.: Harvard University Press.

[24] Sullenger, K., Turner, S., Caplan, H., Crummey, J., Cuming, R., Charron, C., \& Corey, B. (2000). Culture Wars in the Classroom: Prospective Teachers Question Science. Journal of Research in Science Teaching, 37(9), 895-915.

[25] The Pew Forum on Religion and Public Life. (2007). Is There A Culture War? A Dialogue on Values and American Public Life. Executive Summary. Retrieved April 7, 2017, from http:// people.uncw.edu/lowery/pls405/Textbook_chapter_outlines/culturewar-execsum.pdf

[26] World Values Survey Association. (n.d.). World Value Survey. Findings and Insights. Retrieved May 29, 2020, from http://www.worldvaluessurvey.org/WVSContents.jsp

[27] Zimmerman, J. (2005). Whose America?: Culture wars in the public schools. Cambridge, MA, London: Harvard University Press. 